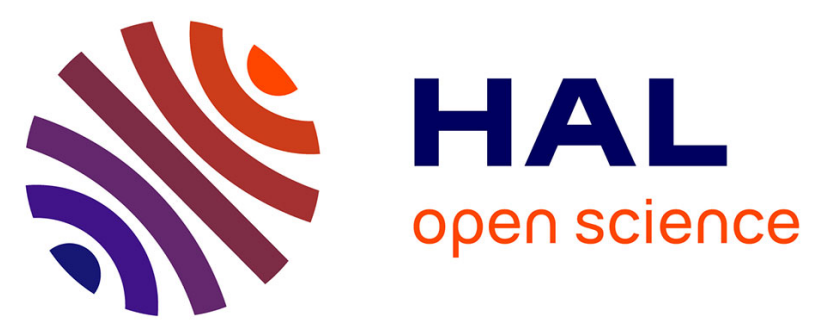

\title{
Electrocardiographic and hemodynamic effects of intravenous infusion of bupivacaine, ropivacaine, levobupivacaine, and lidocaine in anesthetized ewes.
}

Patrick Guinet, Jean-Pierre Estebe, Maja Ratajczak-Enselme, Jean-Yves Y. Bansard, François Chevanne, David Bec, Pascal Lecorre, Eric Wodey, Claude Ecoffey

\section{To cite this version:}

Patrick Guinet, Jean-Pierre Estebe, Maja Ratajczak-Enselme, Jean-Yves Y. Bansard, François Chevanne, et al.. Electrocardiographic and hemodynamic effects of intravenous infusion of bupivacaine, ropivacaine, levobupivacaine, and lidocaine in anesthetized ewes.. Regional Anesthesia and Pain Medicine, 2009, 34 (1), pp.17-23. 10.1097/AAP.0b013e31819338e2 . inserm-00382380

\section{HAL Id: inserm-00382380 https://www.hal.inserm.fr/inserm-00382380}

Submitted on 2 Jul 2009

HAL is a multi-disciplinary open access archive for the deposit and dissemination of scientific research documents, whether they are published or not. The documents may come from teaching and research institutions in France or abroad, or from public or private research centers.
L'archive ouverte pluridisciplinaire HAL, est destinée au dépôt et à la diffusion de documents scientifiques de niveau recherche, publiés ou non, émanant des établissements d'enseignement et de recherche français ou étrangers, des laboratoires publics ou privés. 
TITLE PAGE

ELECTROCARDIOGRAPHIC AND HEMODYNAMIC EFFECTS OF INTRAVENOUS INFUSION OF BUPIVACAINE, ROPIVACAINE, LEVOBUPIVACAINE AND LIDOCAINE IN ANESTHETIZED EWES.

Patrick Guinet $^{1,3,4}, \mathrm{MD}$, Jean-Pierre Estebe ${ }^{1,3}, \mathrm{MD}, \mathrm{PhD}$, Maja Ratajczak-Enselme ${ }^{3}$, PharmD, Jean-Yves Bansard ${ }^{2,4}, \mathrm{PhD}$, François Chevanne ${ }^{3}, \mathrm{BS}$, David $\mathrm{Bec}^{3}$, BS, Pascal Lecorre ${ }^{3}$, PharmD, PhD, Eric Wodey ${ }^{1,3,4}, \mathrm{MD}, \mathrm{Ph}$ D, Claude Ecoffey ${ }^{1}, \mathrm{MD}$.

${ }^{1}$ Service d'Anesthésie Réanimation Chirurgicale 2, CHU de Rennes, France ;

${ }^{2}$ Université de Rennes 1, Laboratoire de Traitement du Signal et de l'Image (LTSI), France ;

${ }^{3}$ Laboratoire de Pharmacie Galénique, Biopharmacie et Pharmacie Clinique, UPRES EA ; 3892, Facultés des Sciences Pharmaceutiques et Biologiques, Université de Rennes 1, France ${ }^{4}$ INSERM U 642, Rennes, France ;

\section{CORRESPONDING AUTHOR:}

Guinet Patrick, MD. Service d'Anesthésie Réanimation Chirurgicale 2, CHU de Rennes, 2 rue Henri Le Guillou, 35000 Rennes, FRANCE

Email : patrick.guinet@chu-rennes.fr. Phone: 33(0)299282422. Fax: 33(0)299282421 


\section{ABSTRACT}

Background and Objectives: Neural blockade techniques are associated with a risk of acute cardiac toxicity after accidental intravenous (IV) injection of local anesthetics (LAs). The aim of this study was to compare electrocardiographic (ECG) and hemodynamic (HEM) effects induced by IV infusion of LAs in an anesthetized ewe model.

Methods: Thirty-two anesthetized ewes received IV bupivacaine (BUPI), ropivacaine (ROPI), or levobupivacaine (S-BUPI) at an equimolar dose, or lidocaine (LIDO) at a three fold higher rate ( $\mathrm{n}=8$ in each group). Intervals $\mathrm{RR}, \mathrm{PR}, \mathrm{QRS}, \mathrm{QT}$, corrected QT $\left(\mathrm{QT}_{\mathrm{c}}\right)$, changes in systolic and diastolic arterial pressure $(\triangle \mathrm{SAP}$ and $\triangle \mathrm{DAP})$ and in myocardial contractility $(\Delta \mathrm{dP} / \mathrm{dt})$, were assessed every 30 seconds for 7 min. From main ECG variables (RR, PR, QRS, QT), we proposed to use multiple correspondence analysis (MCA) and hierarchical ascending classification (HAC) to explore the structure of statistical dependencies among those measurements, and to determine the different patterns of ECG and HEM changes induced by infusion of BUPI, ROPI, S-BUPI and LIDO.

Results: Graphic representation of MCA associated BUPI with the most pronounced modifications in ECG and HEM variables, followed in decreasing order by ROPI, S-BUPI, LIDO. Comparisons of clusters identified by HAC confirmed this classification for ECG variables. Ventricular tachycardia occurred only in BUPI group.

Conclusion: In our anesthetized ewe model, high dose IV infusion of BUPI induced the most marked changes in RR, PR, QRS, QT, $\mathrm{QT}_{\mathrm{C}}$ intervals, $\Delta \mathrm{SAP}$ and $\Delta \mathrm{dP} / \mathrm{dt}$. ROPI altered ECG variables less than BUPI but more than S-BUPI. LIDO was associated with the smallest changes.

Keywords: Animal experiment, local anesthetics, cardiovascular toxicity, multiple correspondence analysis 


\section{TEXT}

\section{Introduction}

The descriptions of several cardiac arrests following an accidental intra-venous (IV) injection of bupivacaine during peripheral nerve blockade or epidural anesthesia (1) have led to the development of new compounds, such as ropivacaine and levobupivacaine.

The greater security provided by these single S-enantiomers compared with bupivacaine is supported by several studies, on isolated heart (2), awake or anesthetized animals (3-5). Higher IV doses of ropivacaine and levobupivacaine than racemic bupivacaine are required to induce central nervous system (CNS) effects and cardiovascular (CV) disturbances (impairment of atrio-ventricular conduction, decreased myocardial contractility) (3-5). Nevertheless descriptions of cardiovascular accidents with ropivacaine (6) and levobupivacaine (7) compels to keep in mind the remaining narrow safety margin of these drugs.

Studies on healthy volunteers are limited by the necessarily low doses of local anesthetics (LAs) administrated IV (8), markedly lower than doses used in clinical practice for neuraxial blockade. Therefore assessment of cardiovascular effects of LAs requires animal models. An anesthetized animal model decreases the overlap between neurologic and cardiovascular toxicity, as the latter is increased by hypoxia, hypercarbia and acidosis related to convulsions primarily occuring in awake animals (9).

The aim of this study was to describe and compare electrocardiographic and hemodynamic effects induced by high doses of LAs (bupivacaine, ropivacaine, levobupivacaine and lidocaine) administrated IV in an anesthetized ewe model. 


\section{Materials and Methods}

The study was performed according to a protocol approved by the Local Committee of Laboratory Investigation and Animal Care of our institution and achieved in accordance with the rules and guidelines concerning the care and the use for laboratory animal experiments (agreement $n^{\circ}$ B35-238-21). Experiments were performed on 32 non-pregnant Lacaune ewes (mean weight: $57 \mathrm{~kg}$, range $48-74 \mathrm{~kg}$ ) which were obtained from INRA (Saint Gilles, France, authorization number Fr 35240 046).

\section{Animal preparation}

Ewes were anesthetized with an IV injection of thiopental $(5-8 \mathrm{mg} / \mathrm{kg})$ through a catheter inserted in the right jugular vein. Animals were intubated, and ventilation was controlled mechanically (end-tidal $\mathrm{CO} 235 \mathrm{mmHg}$ ). Throughout the experiment, anesthesia was maintained with isoflurane $1.5 \%$ in oxygen/air $(50 \% / 50 \%)$. Isoflurane coud be transciently increased to a maximum of $2 \%$ or decreased to a minimum of $1 \%$ in case of movements or progressive decrease in blood pressure respectively. Another catheter was inserted in the left jugular vein for blood sampling, and administration of maintenance fluid. A standard electrocardiogram (ECG) was continuously recorded, and arterial blood pressure was monitored invasively through a 20G radial arterial catheter (Leader Cath-Vygon). A simplified electroencephalogram (EEG) (two parietal and two occipital electrodes) was also recorded in order to detect any convulsive pattern. Body temperature was checked by an oesophageal thermistor, and a heat lamp was used to maintain body temperature above $37.5^{\circ} \mathrm{C}$. IV administration of LAs was performed when hemodynamic parameters were stabilized, after at least one hour of general anesthesia.

\section{Local anesthetic experiments}

In a preliminary study, the dose of ropivacaine hydrochloride needed to obtain a cardiac arrest after an IV administration of six minutes had been determined at $1.43 \mathrm{mg} / \mathrm{kg} / \mathrm{min}$. 
The first group of ewes was administered IV ropivacaine hydrochloride $(\mathrm{HCl})(\mathrm{ROPI}, \mathrm{n}=8)$ at the dose determined above, over 6 minutes. Bupivacaine (BUPI, $n=8$ ) and levobupivacaine (S-BUPI, $\mathrm{n}=8$ ) groups were administered an equimolar dose of the respective LAs Hcl over 6 minutes $(1.49 \mathrm{mg} / \mathrm{kg} / \mathrm{min}$ or $4.58 \mu \mathrm{mol} / \mathrm{kg} / \mathrm{min})$. The last group received lidocaine $(\mathrm{HCl})$ (LIDO, $\mathrm{n}=8)$ at a three fold equimolar rate $(3.74 \mathrm{mg} / \mathrm{kg} / \mathrm{min}$ or $13.77 \mu \mathrm{mol} / \mathrm{kg} / \mathrm{min}$ over 6 minutes) in order to respect the potency of LAs (10). The mean doses were 502mg, (range 412-635mg) for the ROPI, BUPI and S-BUPI groups and 1393mg (range 1235-1544mg) for the LIDO group.

Plasma concentrations of LAs were determined every minute using High Performance Liquid Chromatography (HPLC). Blood samples were collected in $4.5 \mathrm{ml}$ under vacuum vials containing $0.054 \mathrm{ml}$ of a $15 \% \mathrm{~K} 3 \mathrm{E}$ anticoagulant solution (Vacutainer $\mathrm{TM}$, Becton Dickinson, Plymouth, UK). After centrifugation at 3500 x G for $10 \mathrm{~min}$, plasma was stored in polyethylene tubes at $-20^{\circ} \mathrm{C}$ until analysis. Ropivacaine, bupivacaine, levobupivacaine and lidocaine were extracted from plasma according to a previously published method with slight modifications (11). Briefly, $0.5 \mathrm{ml}$ of plasma sample were alkalinized by $50 \mu 1$ of $1 \mathrm{M} \mathrm{NaOH}$ and $3 \mathrm{ml}$ of $\mathrm{n}$-Heptane were added, after horizontal shaking ( $3 \mathrm{~min}$ ) and centrifugation ( $3 \mathrm{~min}$ at $3500 \mathrm{~g}$ ), the organic phase was transferred to a conical vial containing $50 \mu 1$ of $0.05 \mathrm{M}$ H2SO4. After similar shaking and centrifugation, the organic phase was discarded, and the aqueous phase was buffered with $10 \mu \mathrm{L}$ of $0.5 \mathrm{M} \mathrm{K} 2 \mathrm{HPO} 4$ and $40 \mu \mathrm{L}$ were injected onto the chromatographic system. The chromatographic system consisted in a Milton Roy model spectromonitor-3 UV detector (LDC Milton Roy, Riviera Beach, FL, USA), a Waters Model pump, a Waters Model 717 automatic injector and a Waters Empower-Pro data acquisition system (Waters Assoc., Milford, MA, USA). The analytical chromatographic column was a Lichrocat-Lichrospher RP-B Merck cartridge (length $125 \mathrm{~mm}$, internal diameter $3 \mathrm{~mm}$ ). The flow rate was $0.5 \mathrm{ml} / \mathrm{min}$, and the temperature was maintained at $30^{\circ} \mathrm{C}$. The mobile phase 
consisted of a mixture of acetonitrile $(23 \%)$ and a $10 \mathrm{mM}$ sodium dihydrogenphosphate and $8.7 \mathrm{mM}$ orthophosphoric acid aqueous solution, $\mathrm{pH} 2.1$ (77\%).

\section{Electrocardiographic and hemodynamic measurements}

ECG, invasive arterial pressure (systolic arterial pressure (SAP), and diastolic arterial pressure (DAP)), and EEG were obtained continuously and recorded on a personal computer with Chart (Chart 5.0 software, AD Instruments, Castle Hill, NSW, Australia), and sampled at 400 Hz. ECG variables :RR, PR, QRS, QT intervals (ms), corrected QT using Bazett's formula $\left(\mathrm{QT}_{\mathrm{C}}=\mathrm{QTXRR}^{-0,5}, \mathrm{~ms}\right)$, and hemodynamic variables $(\mathrm{HEM})$ : SAP and DAP $(\mathrm{mmHg})$ and $\mathrm{dP} / \mathrm{dt}$ (maximum rate of rise in arterial pressure, $\mathrm{mmHg} / \mathrm{ms}$ ), reflecting the myocardial contractility, were assessed one minute before (T0-60sec, baseline data) and every 30 seconds during seven minutes (last measurement: $\mathrm{T} 0+420 \mathrm{sec}$ ) following the beginning of IV injection (T0). Changes in HEM variables compared to baseline were determined at each time point $(\Delta \mathrm{SAP}, \Delta \mathrm{DAP}, \Delta \mathrm{dP} / \mathrm{dt})$. Onsets of asystoly, electromechanical dissociation, ventricular tachycardia or fibrillation were also noted for each ewe.

\section{Statistical analysis}

The objective of this analysis was to describe ECG and HEM changes over time after IV infusion of four different LAs in anesthetized ewes.

Main variables of this analysis were RR, PR, QRS, and QT intervals measured on ECG at each time of the procedure. In order to establish the underlying structure between these variables, relations between them were calculated and visualised on a graph, using Multiple Correspondence Analysis (MCA) (12). On the model obtained, secondary variables were showed, such as the type of LA infused, times of the procedure, and other ECG and HEM variables (corrected $\mathrm{QT}, \Delta \mathrm{SAP}, \Delta \mathrm{DAP}, \Delta \mathrm{dP} / \mathrm{dt}$ ). 
The interpretation of the analysis was then enriched by identification of different clusters of ewes, using Hierarchical Ascending Classification (HAC) (13).

MCA and HAC allowed this methodological approach, while respecting the relationships between analysed variables, wether they were linear or not.

\section{Multiple Correspondence Analysis and Hierarchical Ascending Classification}

\section{Homogenization of variables}

First of all, a classification of continuous variables according to the fuzzy coding method was performed (14). In this method, each variable was segmented according to its quartile values. Then, for each constituted class of principal ECG variables, a new class was created by overlapping two contiguous classes. This permited the retention of the same numbers in each class and preserved the notion of distribution around the median.

\section{Generation of the contingency table}

MCA relies on the analysis of a contingency table, where each element describes the number of observed individuals partitioned among the modalities of qualitative variables. In our study, the qualitative variables were the four principal ECG variables (RR, PR, QRS, QT), coded following the method described above.

\section{Basics of MCA estimates}

From the contingency table obtained, MCA estimated relationships between distribution profiles. Similarities between profiles were taken into account by using a $\chi^{2}$ metric. The $\chi^{2}$ distance is a well known similarity measure of statistical dependence between qualitative variables. Such metric made it possible to compare shapes of distribution profiles, providing an analysis of the underlying structure of statistical dependencies among ECG variables.

ECG variables were represented by their projections on the first principal components (i.e. axis 1 and 2). 
On this graph were then showed secondary variables: type of LA infused, times of the procedure, corrected $\mathrm{QT}$, and changes in HEM variables $(\Delta \mathrm{SAP}, \Delta \mathrm{DAP}, \Delta \mathrm{dP} / \mathrm{dt})$. To help interpretation, barycentre (center of mass) of each group of ewes (BUPI, ROPI, S-BUPI, LIDO) was projected on the two first principal components (axis 1 and 2).

HAC

HAC was applied on MCA principal components to extract groups of ECG variables considered as neighbours. A classification tree of neighbour points was obtained (dendogram). These clusters were then analyzed for each variable studied (main and secondary variables) in term of the positions of each cluster on the structured model, using Mann-Whitney U test, because the variables studied did not have a normal distribution.

All statistical analyses were performed with the BIC LOGINSERM 1979/1987 software.

Statistical results were considered significant when $\mathrm{p}<0.05$.

\section{Results}

Among the four groups of ewes, there was no significant difference either in weight or in baseline data (T0-60sec) for ECG and HEM variables (table 1).

No convulsive pattern was observed on EEG during and after IV infusion of LAs.

\section{Multiple Correspondence Analysis}

Projection of the main variables on the first two principal components is shown on figure 1a. Analysis of structure provided by MCA from principal variables (RR, PR, QRS, QT) showed a distribution following the axis one. Low values of principal variables were observed on the right of the graph (RR1, PR1, QRS1, QT1), and high values on the left (RR7, etc.).

The same disposition was observed for secondary variables $\left(\mathrm{QT}_{\mathrm{C}}, \Delta \mathrm{SAP}, \Delta \mathrm{DAP}, \Delta \mathrm{dP} / \mathrm{dt}\right)$, with low values on the right $\left(\mathrm{QT}_{\mathrm{C}} 1, \Delta \mathrm{SAP} 1, \Delta \mathrm{DAP} 1, \Delta \mathrm{dP} / \mathrm{dt} 1\right)$ and high values on the left (QT 4 , etc.) (figure 2). 
Barycentres (centers of mass) of each group of LA were determined and followed globally the horizontal axis (axis 1) with respectively from right to left: LIDO, S-BUPI, ROPI and BUPI (figure 1b). Barycentres of each time point of the procedure were also following the axis one, with baseline and early sequences on the right, and late sequences on the left $(\mathrm{T} 0+90 \mathrm{sec}$ to $\mathrm{T} 0+420 \mathrm{sec}$ ) (figure $1 \mathrm{~b}$ and 2 ).

Therefore MCA established a link between the drug infused and ECG and HEM changes. The smallest alterations of RR, PR, QRS, QT, $\mathrm{QT}_{\mathrm{C}}$ intervals, changes in SAP, DAP and changes in myocardial contractility were associated with the LIDO group, followed in increasing alterations order by S-BUPI, ROPI, and BUPI groups.

\section{Hierarchical Ascending Classification}

HAC identified 6 clusters in the correspondence analysis (figure 3, top). Clusters 1 and 2 were characterized by their prominence in high values of ECG variables and HEM changes compared to clusters 3 to 6 (figure 3, bottom: dendogram). Dots from cluster 1 mainly originated in the BUPI group and showed the highest values for ECG variables and HEM changes compared to other subsets $(\mathrm{p}<0.05)$ (figure 4$)$. The lowest values and changes were in cluster $6(\mathrm{p}<0.05)$, coming mainly from the LIDO group. Dots from cluster 2 stemmed mainly from the ROPI group, with lower ECG and HEM alterations than in cluster $1(p<0.05)$ and

more pronounced alterations than in clusters 3 (except for QRS interval), 5 and 6. S-BUPI was widely present in cluster 3, although not prominent; in the latter, ECG changes were lower than in cluster $2(\mathrm{p}<0.05)$, conversely there was no significant changes in HEM parameters compared to cluster 2 (figure 4).

Mortality was not different between BUPI, ROPI and S-BUPI groups. Although a three fold higher infusion was used in the LIDO group, seven of eight ewes survived. Ventricular tachycardia occurred in three ewes from the BUPI group, but was not seen in ROPI and SBUPI groups. Abrupt onset of asystoly was observed in respectively two and four of eight 
ewes in BUPI and ROPI groups, and electromechanical dissociation was the first impairment observed in respectively two, three and eight of eight ewes in the BUPI, ROPI and S-BUPI groups. Ventricular tachycardia, asystoly or electromechanical dissociation occurred 2 min or more after the end of IV infusion in ROPI, S-BUPI and LIDO groups. Conversely, in BUPI groups, severe dysrythmias occurred before the end of IV infusion in 3 of 8 ewes.

\section{Plasma concentrations}

Plasma concentrations of LA $(\mu \mathrm{g} / \mathrm{ml})$ reflected ECG and HEM alterations (figure 5). Concentrations of BUPI, ROPI and S-BUPI were homogeneous during the first 4 minutes following the beginning of IV infusion. Conversely, a large inter-individual variation was observed after the $4^{\text {th }}$ minute, especially in the S-BUPI and LIDO groups.

\section{Discussion}

The main findings of this study are 1) the less pronounced ECG and HEM alterations induced by single S-enantiomers compared to racemic bupivacaine, 2) the unexpectedly less marked ECG alterations induced by levobupivacaine compared to ropivacaine, 3) the slight alterations induced by lidocaine despite the high dose infused.

To our knowledge this is the first study of the effects of IV infusion of LAs on an anesthetized ewe model. Although far from situations that can be met in clinical practice, our model and the statistical method used allows us to obtain patterns of ECG and HEM changes over time induced by high doses IV LAs infusion. Studies conducted on conscious sheep, a better model for simulation of an accidental IV injection of LA, are not able to describe fully the cardiovascular effects because of primary induced CNS effects (15). Onset of convulsions results in tachycardia and hypertension and precludes further assessment of CV alterations induced directly by LAs. Direct left intra-coronary infusion of increasing doses of LAs avoids 
this overlap between CNS and CV effects but cuts off the model from arythmogenic effects of LAs (16).

A significantly less impairment of RR, PR, QRS, QT and $\mathrm{QT}_{\mathrm{C}}$ intervals, and of blood pressure and myocardial contractility was observed in ROPI and S-BUPI groups compared with BUPI group, in agreement with other studies conducted on different models $(2,4,17)$. Even though high doses of IV LAs were infused in our study, ventricular tachycardia occurred only in BUPI group, before the end of the six-minutes IV infusion (3 of eight ewes). Ventricular dysrhythmias were also more frequently observed with bupivacaine when compared to levobupivacaine (17) or to ropivacaine (18). In our study, the occurrence of such ventricular arythmias may have been decreased by interactions between isoflurane used to maintain general anesthesia and LAs, at least in BUPI group (19).

An unexpected result is the lower impairment of ECG variables induced by levobupivacaine compared to ropivacaine. The barycentre position of the S-BUPI group appears unquestionably between the LIDO and ROPI groups on the graphical representation of MCA (figures $1 \mathrm{~b}$ and $2 \mathrm{~b}$ ). Nevertheless, even though a large proportion of dots in cluster 3 identified by HAC originates in S-BUPI group, numerous dots from LIDO group contribute also to this cluster. Therefore direct comparison of cluster 3 with others does not allow firm conclusions. To better understand the alterations observed in our model, we performed a crossed analysis between time, LAs, and clusters identified by HAC. Times of the procedure were divided into four parts ( $\mathrm{T} 1$ : baseline, $\mathrm{T} 2$ : $\mathrm{T} 0+30$ to $\mathrm{T} 0+90 \mathrm{sec}, \mathrm{T} 3: \mathrm{T} 0+120$ to T0+240sec, T4: T0+270 to T0+420sec, with T0: beginning of IV infusion), and we looked at the distribution of ewes according to LAs infused and clusters (table 2). The major observation was that clusters 1 and 2 contain respectively $51.8 \%$ and $50.0 \%$ of ewes from BUPI and ROPI groups at late periods of the experiment (T3+T4 periods), against only $25.0 \%$ 
of ewes from S-BUPI group. Considering the prominence of high alterations in ECG variables in clusters 1 and 2 compared to other clusters (figure 3, bottom: dendogram), this cross analysis confirms the lower impairment of ECG variables by S-BUPI compared to BUPI and ROPI in our study. Conversely HEM changes induced by S-BUPI are not significantly different from those induced by ROPI (figure 4, clusters 2 and 3).

Similar doses of levobupivacaine and ropivacaine are required to induce a cardiac arrest (16), although numerous studies document intermediate cardiovascular effects of levobupivacaine, between bupivacaine and ropivacaine. On an isolated rabbit heart model, Mazoit and collaborators (2) reported an increase in QRS duration in the respective ratio of 1:0.4:0.3 for racemic bupivacaine, levobupivacaine and ropivacaine respectively. In a rat model, Ohmura and collaborators (20) observed that the cumulative doses of bupivacaine, levobupivacaine and ropivacaine necessary to induce dysrythmia were respectively $1: 3.3: 6.9$. This discrepancy between our study and others could be explained partly by the higher lipophilicity of levobupivacaine compared to ropivacaine, resulting in a higher pulmonary uptake (21). This larger pulmonary uptake observed by Ohmura and co-workers in anesthetized rabbits was associated with a lower maximal plasma level of levobupivacaine compared to ropivacaine. Nevertheless this was not observed in our study, where plasma level were relatively similar and homogeneous during the first 4 minutes of IV infusion (figure 5).

Another surprising result is the proximity between barycentres of ROPI and BUPI groups observed after MCA. A more pronounced difference between these 2 drugs was expected, even if comparisons of clusters 1 (mainly originating in BUPI group) and 2 (mainly originating in ROPI group) confirms a significantly lower impairment of ECG and HEM parameters induced by ropivacaine compared to bupivacaine. Proximity of these two barycentres in MCA is explained by analysis of cluster 4: indeed dots from this cluster originated mainly in two ewes from BUPI group, whose ECG alterations were quite different 
from other ewes of the group: QRS and overall QT increased only slightly over the course of IV infusion. Nevertheless RR, PR, and HEM changes were similar to changes reported in other ewes from BUPI group, and plasma concentrations of BUPI were not different when compared with concentrations obtained in other ewes of the same group. We had therefore no valuable reason to exclude these 2 ewes from analysis, even if this unexplained effect on QRS and QT results in a deviation on the right of the BUPI barycentre, bringing it close to ROPI group.

Last, our study confirms that high doses of lidocaine are needed to induce ECG and HEM impairments, as observed by other authors. Nine to sixteen times more lidocaine are needed to induce the same ECG alterations than bupivacaine $(15,22)$. Furthermore, only $13.5 \%$ of dots from LIDO group are observed in clusters characterized by pronounced ECG alterations (clusters 1 and 2, table 2) during late periods of the experiment (T3+T4), compared to 25\%, $50 \%$ and $51.8 \%$ for S-BUPI, ROPI and BUPI respectively. Only one ewe from LIDO group presented a severe cardiac consequence under the form of an electromechanical dissociation. Occurrence of ventricular tachycardia with IV lidocaine appears to be rare: none was observed in the studies from Nancarrow and collaborators (3) similarly to what we found in our anesthetized ewe model.

\section{Limitation of the study}

In our study, decision was made to infuse equimolar doses of BUPI, ROPI and S-BUPI. If equipotency between BUPI and S-BUPI is admitted (23), this is not the case for ROPI and BUPI: Polley and collaborators observed that 40 to $50 \%$ more ropivacaine was needed to obtain the same efficacy than bupivacaine when administered epidurally (24). Nevertheless for peripheral blockade, the least potency of ROPI compared with BUPI remains to be demonstrated: for example, duration of anesthesia and analgesia were similar in axillary and 
interscalenic blocks $(25,26)$. Those controversial data lead us to keep equimolar infusions. Increasing the doses of ROPI infused would have likely conducted to more severe impariments of ECG and HEM variables, which would have even enhanced the difference between S-BUPI and ROPI.

Our choice of a 6-min IV infusion under general anaesthesia in ewes has several limitations. First this is not a frequent situation in clinical practice, as continuous perineural infusion is performed with much lower doses than those administered IV in our study. Second, general anaesthesia, especially with inhaled anaesthetics such as isoflurane, can modify the cardiovascular response to LA IV infusion directly through vasodilation and negative inotropic effect, and eventually indirectly through CNS-induced cardiovascular effects. Nevertheless this model provided a reduced overlap between CNS and cardiovascular system as illustrated by the absence of convulsions, and allows a more complete assessment of ECG and HEM changes than in awake animals.

In conclusion, ECG and HEM alterations induced by equimolar IV infusion of BUPI, ROPI and S-BUPI are more pronounced in the BUPI group than in the ROPI and S-BUPI groups. Furthermore, in our anesthetized ewe model, S-BUPI seems to modify ECG variables less than ROPI does, while HEM changes are similar in those two groups. Despite a three times higher dose infused, LIDO is associated with the smallest impairments in ECG and HEM variables.

\section{REFERENCES}

1. Albright GA. Cardiac arrest following regional anesthesia with etidocaine or bupivacaine. Anesthesiology 1979;51:285-7.

2. Mazoit JX, Decaux A, Bouaziz H, Edouard A. Comparative ventricular electrophysiologic effect of racemic bupivacaine, levobupivacaine, and ropivacaine on the isolated rabbit heart. Anesthesiology 2000;93:784-92. 
3. Nancarrow C, Rutten AJ, Runciman WB et al. Myocardial and cerebral drug concentrations and the mechanisms of death after fatal intravenous doses of lidocaine, bupivacaine, and ropivacaine in the sheep. Anesth Analg 1989;69:276-83.

4. Santos AC, DeArmas PI. Systemic toxicity of levobupivacaine, bupivacaine, and ropivacaine during continuous intravenous infusion to nonpregnant and pregnant ewes. Anesthesiology 2001;95:1256-64.

5. Chang DH, Ladd LA, Wilson KA et al. Tolerability of large-dose intravenous levobupivacaine in sheep. Anesth Analg 2000;91:671-9.

6. Chazalon P, Tourtier JP, Villevielle TH, S. et al. Ropivacaine-induced cardiac arrest after peripheral nerve block: successful resuscitation. Anesthesiology 2003;99:144951.

7. Salomaki TE, Laurila PA, Ville J. Successful resuscitation after cardiovascular collapse following accidental intravenous infusion of levobupivacaine during general anesthesia. Anesthesiology 2005;103:1095-6.

8. Stewart J, Kellett N, Castro D. The central nervous system and cardiovascular effects of levobupivacaine and ropivacaine in healthy volunteers. Anesth Analg 2003;97:4126 , table of contents.

9. Rosen MA, Thigpen JW, Shnider SM et al. Bupivacaine-induced cardiotoxicity in hypoxic and acidotic sheep. Anesth Analg 1985;64:1089-96.

10. Jorfeldt L, Lofstrom B, Pernow B, Persson B, Wahren J, Widman B. The effect of local anaesthetics on the central circulation and respiration in man and dog.Acta Anaesthesiol Scand. 1968;12(4):153-69.

11. Reif S, Le Corre P, Dollo G et al. High-performance liquid chromatographic determination of ropivacaine, 3-hydroxy-ropivacaine, 4-hydroxy-ropivacaine and 2',6'pipecoloxylidide in plasma. J Chromatogr B Biomed Sci Appl 1998;719:239-44.

12. Benzecri J.P. L'analyse des données (vol2). L'analyse des correspondances. Ed. Dunod 1973 Paris. And Benzecri J.P. Correspondence Analysis Handbook. New York: Marcel Dekker. 1992.

13. Lebart L, Morineau H, Piron M. Statistique exploratoire multidimensionnelle. Paris, Ed Dunod 1995, pp 185-206.

14. Gallego FS : codage flou en analyse des correspondances. Les cahiers d'analyse des données $1982 ; 7: 413-30$.

15. Rutten AJ, Nancarrow C, Mather LE et al. Hemodynamic and central nervous system effects of intravenous bolus doses of lidocaine, bupivacaine, and ropivacaine in sheep. Anesth Analg 1989;69:291-9.

16. Chang DH, Ladd LA, Copeland $\mathrm{S}$ et al. Direct cardiac effects of intracoronary bupivacaine, levobupivacaine and ropivacaine in the sheep. $\mathrm{Br} \mathrm{J}$ Pharmacol 2001;132:649-58.

17. Huang YF, Pryor ME, Mather LE, Veering BT. Cardiovascular and central nervous system effects of intravenous levobupivacaine and bupivacaine in sheep. Anesth Analg 1998;86:797-804.

18. Lefrant JY, de La Coussaye JE, Ripart J et al. The comparative electrophysiologic and hemodynamic effects of a large dose of ropivacaine and bupivacaine in anesthetized and ventilated piglets. Anesth Analg 2001;93:1598-605, table of contents.

19. Badgwell JM, Heavner JE, Kytta J. Bupivacaine toxicity in young pigs is agedependent and is affected by volatile anesthetics. Anesthesiology 1990;73:297-303.

20. Ohmura S, Kawada $M$, Ohta $T$ et al. Systemic toxicity and resuscitation in bupivacaine-, levobupivacaine-, or ropivacaine-infused rats. Anesth Analg 2001;93:743-8. 
21. Ohmura S, Sugano A, Kawada M, Yamamoto K. Pulmonary uptake of ropivacaine and levobupivacaine in rabbits. Anesth Analg 2003;97:893-7.

22. Nath S, Haggmark S, Johansson G, Reiz S. Differential depressant and electrophysiologic cardiotoxicity of local anesthetics: an experimental study with special reference to lidocaine and bupivacaine. Anesth Analg 1986;65:1263-70.

23. Kopacz DJ, Allen HW, Thompson GE. A comparison of epidural levobupivacaine $0.75 \%$ with racemic bupivacaine for lower abdominal surgery. Anesth Analg 2000;90:642-8.

24. Polley LS, Columb MO, Naughton NN et al. Relative analgesic potencies of ropivacaine and bupivacaine for epidural analgesia in labor: implications for therapeutic indexes. Anesthesiology 1999;90:944-50.

25. Hickey R, Hoffman J, Ramamurthy S. A comparison of ropivacaine $0.5 \%$ and bupivacaine $0.5 \%$ for brachial plexus block. Anesthesiology. 1991;74:639-42.

26. Klein SM, Greengrass RA, Steele SM, D'Ercole FJ, Speer KP, Gleason DH, DeLong ER, Warner DS. A comparison of $0.5 \%$ bupivacaine, $0.5 \%$ ropivacaine, and $0.75 \%$ ropivacaine for interscalene brachial plexus block. Anesth Analg. 1998;87:1316-9. 


\section{LEGENDS FOR ILLUSTRATIONS}

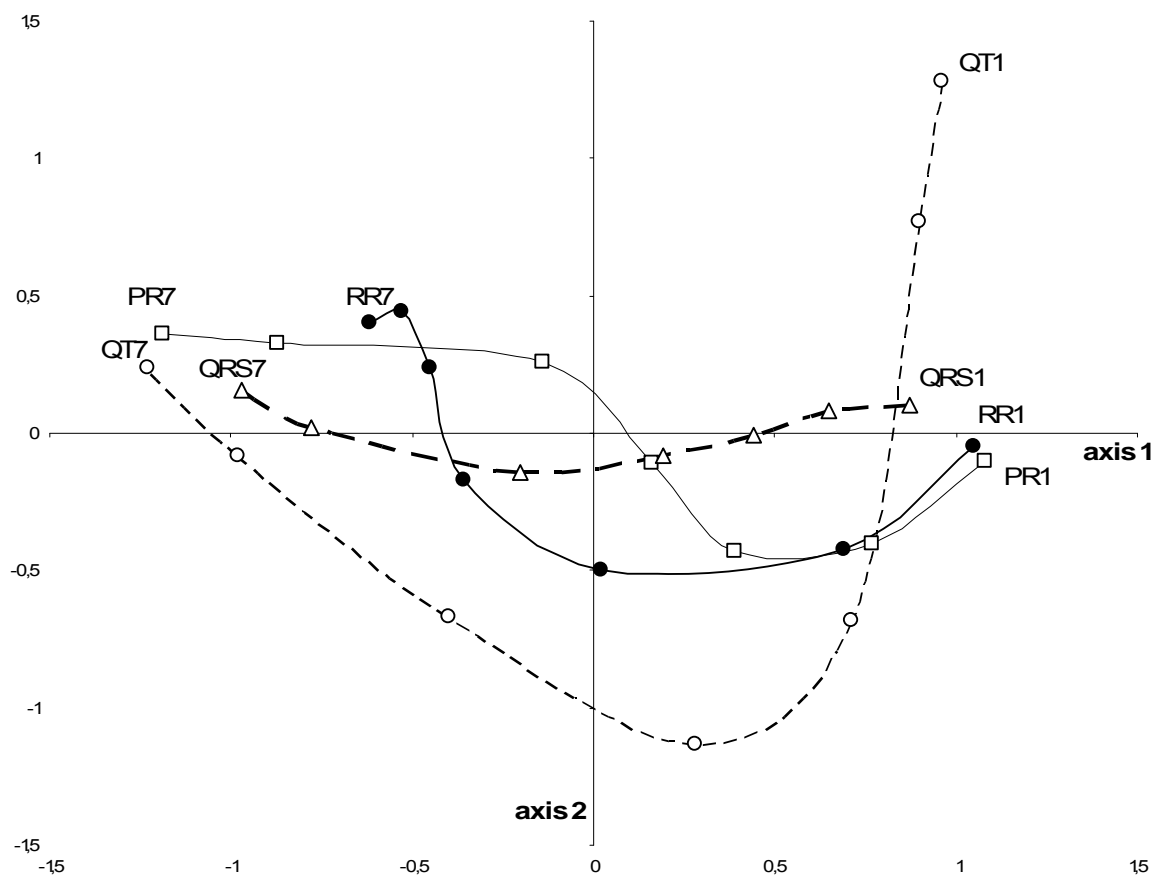

Figure 1a. Ewes were disposed according to the level of resemblance of their ECG variables (RR, PR, QRS, QT) in the multidimensional space of the Multiple Correspondance Analysis using values of the four principal ECG parameters (RR, PR, QRS, QT) measured at each time of the procedure (from T0-60sec to $\mathrm{T} 0+420 \mathrm{sec}$, i.e. 14 points per ewe). ECG variables were globally following axis 1. Low values were on the right (parameters with number 1: RR1, QRS1...), high values on the left (parameters with number 7). 


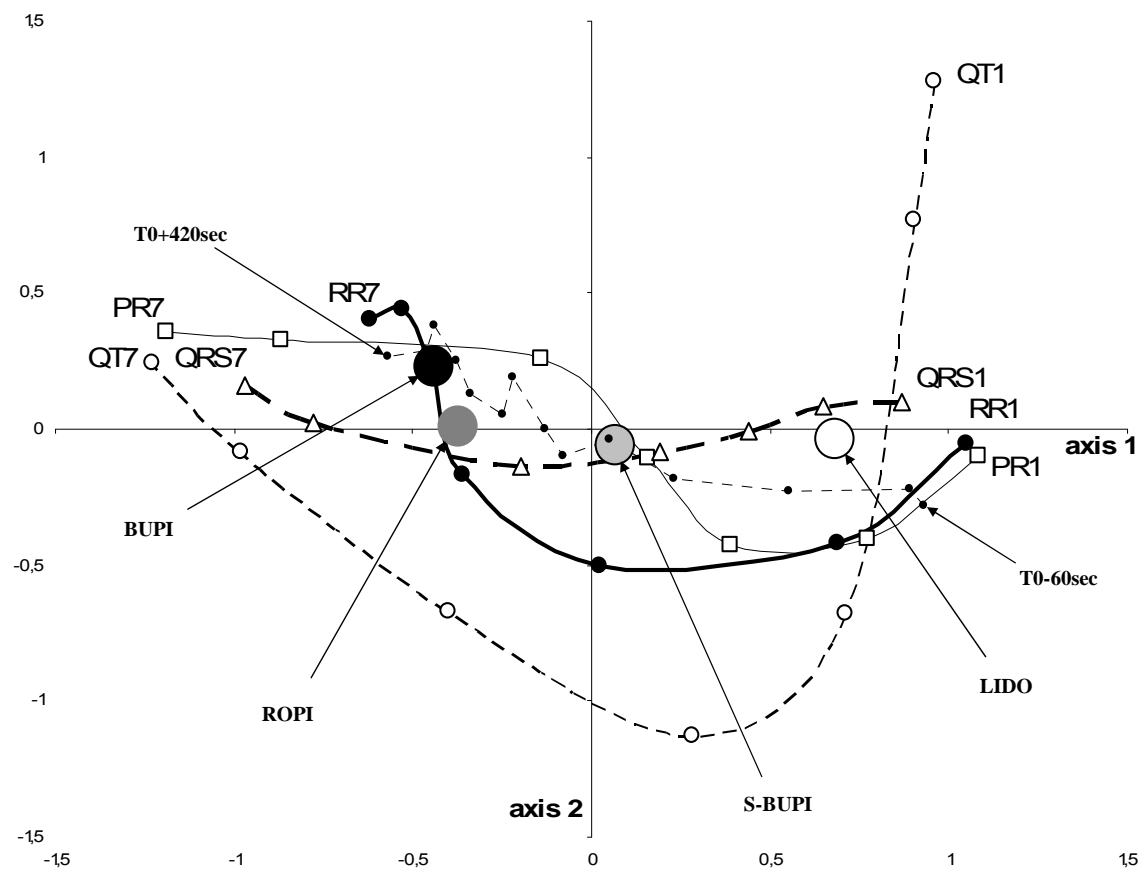

Figure 1b. The barycentre of each group of LAs (BUPI, ROPI, S-BUPI, LIDO, used as secondary variables) was then determined in the MCA. We could observe a distribution of those barycentres along axis 1 . Barycentres of successive time points of the procedure were also drawn on the graph. Time was also following the axis 1, with baseline (T0-60sec) and early sequences of the procedure on the right, and later sequences on the left $(\mathrm{T} 0+90 \mathrm{sec}$ to $\mathrm{T} 0+420 \mathrm{sec})$. 


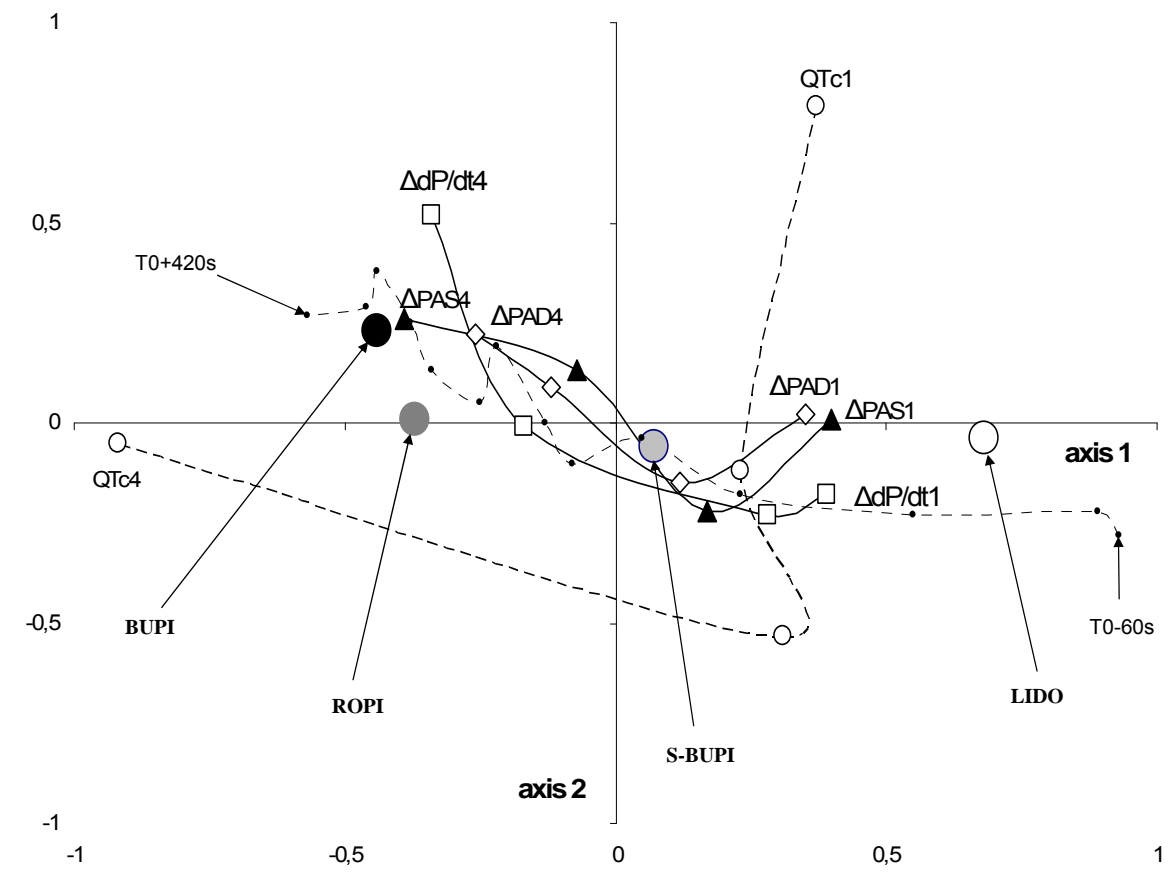

Figure 2. Graphic representation of MCA using LAs, time, $\mathrm{QT}_{\mathrm{C}}, \Delta \mathrm{PAS}, \Delta \mathrm{PAD}, \Delta \mathrm{dP} / \mathrm{dt}$ as secondary variables. The distribution of HEM variables in MCA was also following globally the axis 1 . Low values were on the right (parameters with number 1), high values on the left (parameters with number 4). 


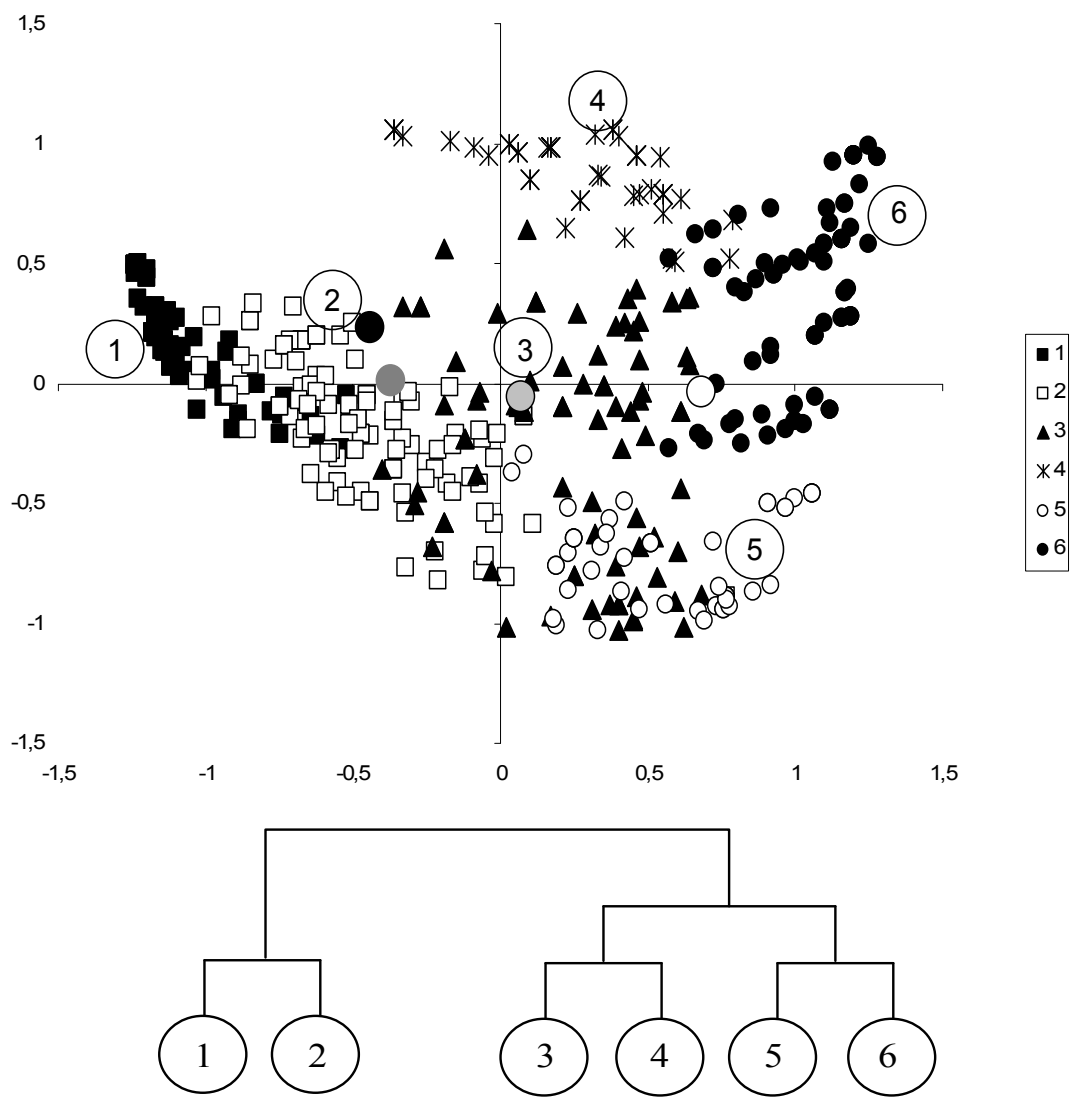

Figure 3, top. Clusters identified by Hierarchical Ascending Classification (1 to 6).

Ewes disposed by MCA were allocated to homogeneous subsets according to their level of resemblance considering principal ECG variables. 6 clusters were identified, whose composition is detailed in Figure 6. $\mathbf{~ : ~ c l u s t e r ~ 1 . ~} \square:$ cluster 2. $\boldsymbol{\Delta}$ : cluster 3. * : cluster 4. $\circ:$ cluster $5 . \bullet:$ cluster 6 .

Figure 3, bottom. Dendogram resulting from HAC. Among the homogeneous clusters distinguished by HAC, a main caesura was evidenced between clusters 1 and 2 on one hand, with pronounced alterations of principal ECG variables, and clusters 3 to 6 on the other hand, with less marked alterations (clusters 3 and 4: intermediary alterations, clusters 5 and 6: moderate alterations). 
Variables

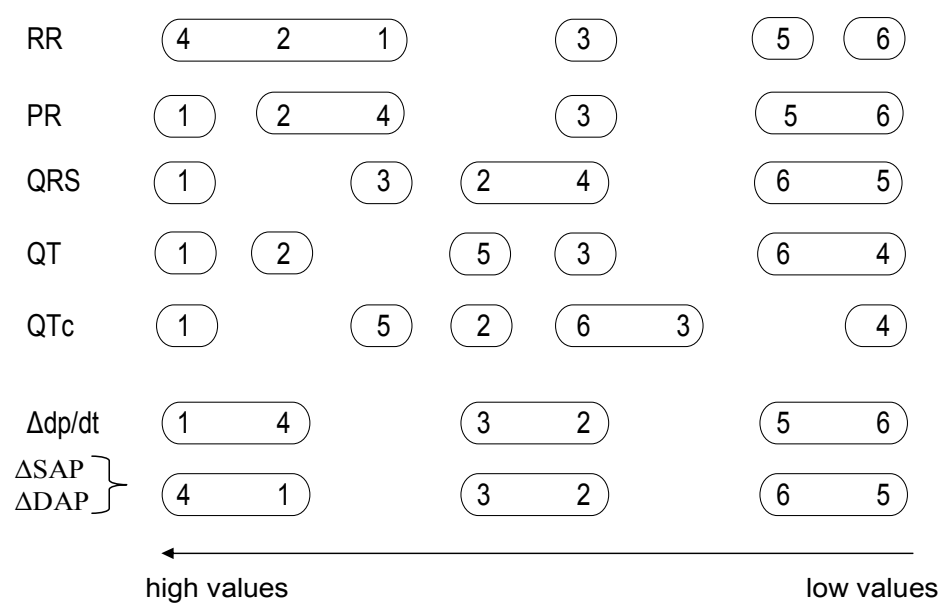

Figure 4. Comparisons of ECG and HEM variables between the 6 clusters identified by Hierarchical Ascending Classification. High values are on the left, low values on the right. Significant differences between clusters regarding ECG and HEM variables are shown.

For example, using a Mann-Whitney test, the relationship established between RR interval and types of LAs infused was confirmed by the significant difference in RR lenght between clusters 1, 2 and 4 (originating respectively mainly in ROPI and BUPI groups) and respectively cluster 3 (mixed subset from LIDO and S-BUPI groups), and clusters 5 and 6 (originating mainly in LIDO group).

: cluster or group of clusters significantly different $(p<0.05)$ from others in term of each variable. 


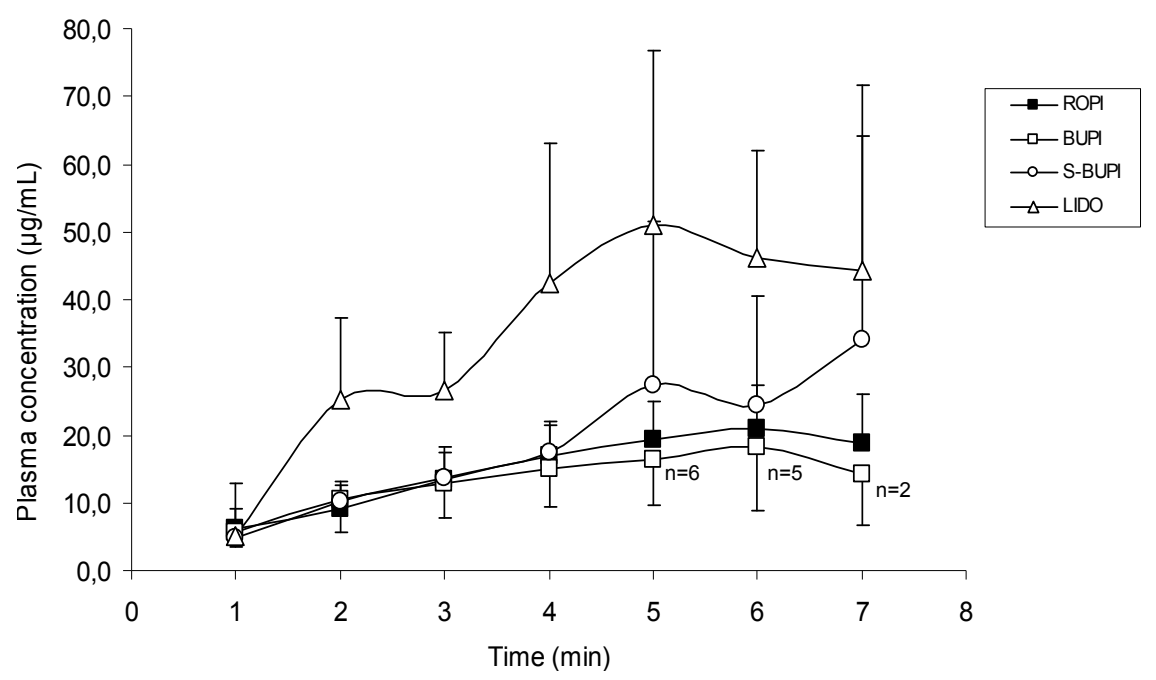

Figure 5. Plasma concentrations ( $\mu \mathrm{g} / \mathrm{ml}$, mean \pm SD) of bupivacaine ( $\square)$, ropivacaine $(\square)$, Sbupivacaine ( $(\circ)$ and lidocaine $(\Delta)$ measured each minute during IV infusion (min 1 to $\min 6$ ) and one minute after the end of infusion. $n=8$ in each group. $n$ decreased progressively in BUPI group related to severe dysrythmias occurring before the end of IV infusion. 


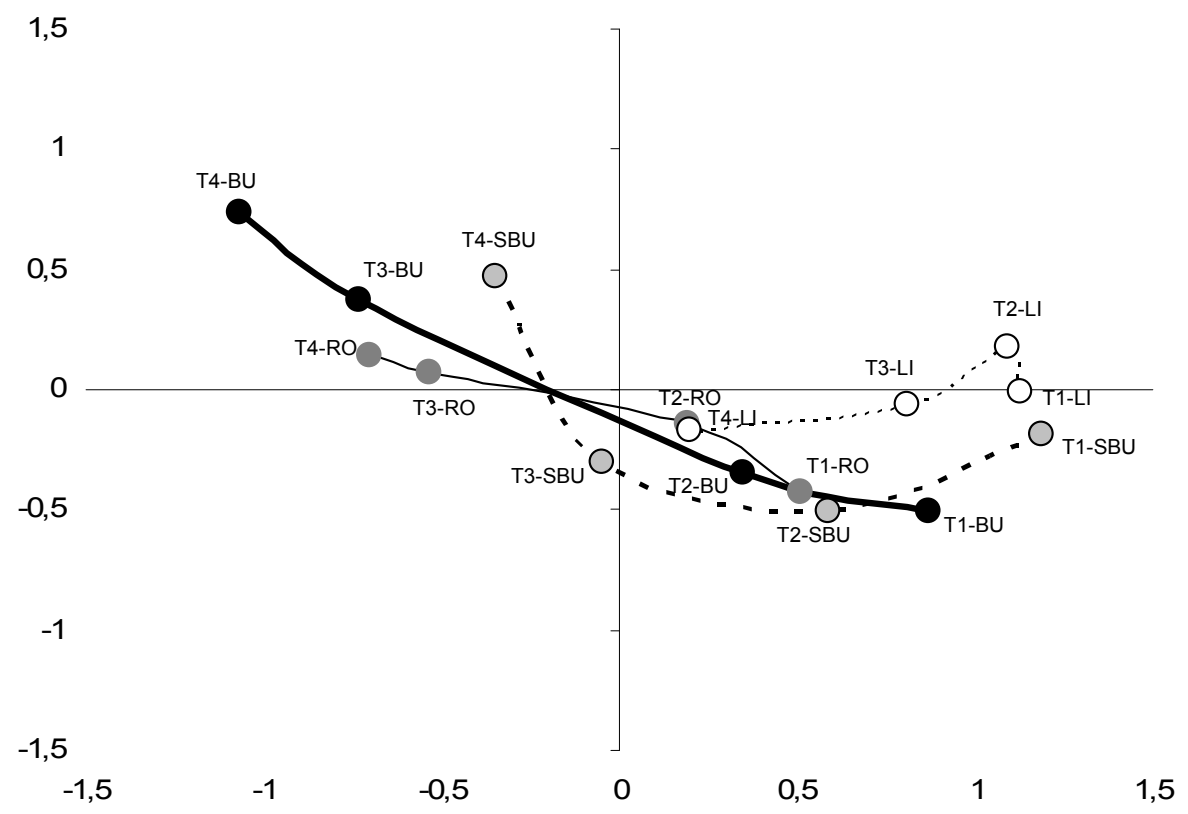

Figure 6. Cross analysis between groups (BUPI, ROPI, S-BUPI, LIDO) and periods of the experiment: $\mathrm{T} 1$ : baseline (T0-60sec), T2: $\mathrm{T} 0+30 \mathrm{sec}$ to $\mathrm{T} 0+90 \mathrm{sec}, \mathrm{T} 3: \mathrm{T} 0+120 \mathrm{sec}$ to $\mathrm{T} 0+240 \mathrm{sec}, \mathrm{T} 4: \mathrm{T} 0+270$ to $\mathrm{T} 0+420 \mathrm{sec}$ (T0 : beginning of IV infusion). 
Table 1. Weight (mean $\pm \mathrm{SD}), \mathrm{ECG}$ variables $\left(\mathrm{RR}, \mathrm{PR}, \mathrm{QRS}, \mathrm{QT}, \mathrm{QT} \mathrm{T}_{\mathrm{C}}: \mathrm{ms}\right.$, mean $\left.\pm \mathrm{SD}\right)$ and hemodynamic variables (SAP and DAP: $\mathrm{mmHg}$, mean $\pm \mathrm{SE}, \mathrm{dP} / \mathrm{dt}: \mathrm{mmHg} / \mathrm{ms}, \operatorname{mean} \pm \mathrm{SD}$ ) before i.v. infusion of LAs in each group. There was no significant difference between groups.

\begin{tabular}{|c|c|c|c|c|c|c|c|c|c|}
\hline & $\begin{array}{c}\text { Weight } \\
(\mathrm{kg}, \\
\mathrm{mean} \pm \mathrm{SD})\end{array}$ & $\begin{array}{c}\mathrm{RR} \\
(\mathrm{ms}, \\
\mathrm{mean} \pm \mathrm{SD})\end{array}$ & $\begin{array}{c}\mathrm{PR} \\
(\mathrm{ms}, \\
\mathrm{mean} \pm \mathrm{SD})\end{array}$ & $\begin{array}{c}\mathrm{QRS} \\
(\mathrm{ms}, \\
\mathrm{mean} \pm \mathrm{SD})\end{array}$ & $\begin{array}{c}\mathrm{QT} \\
(\mathrm{ms}, \\
\mathrm{mean} \pm \mathrm{SD})\end{array}$ & $\begin{array}{c}\mathrm{QT} \\
(\mathrm{ms}, \\
\mathrm{mean} \pm \mathrm{SD})\end{array}$ & $\begin{array}{c}\mathrm{SAP} \\
(\mathrm{mmHg} \\
\mathrm{mean} \pm \mathrm{SD})\end{array}$ & $\begin{array}{c}\mathrm{DAP} \\
(\mathrm{mmHg} \\
\mathrm{mean} \pm \mathrm{SD})\end{array}$ & $\begin{array}{c}\mathrm{dP} / \mathrm{dt} \\
(\mathrm{mmHg} / \mathrm{ms} \\
\mathrm{mean} \pm \mathrm{SD})\end{array}$ \\
\hline BUPI & $59.6 \pm 11.0$ & $617 \pm 87$ & $115 \pm 7$ & $59 \pm 14$ & $360 \pm 35$ & $464 \pm 60$ & $101 \pm 11$ & $79 \pm 13$ & $0.25 \pm 0.04$ \\
\hline ROPI & $59.6 \pm 7.7$ & $641 \pm 151$ & $122 \pm 29$ & $54 \pm 15$ & $360 \pm 75$ & $449 \pm 56$ & $104 \pm 20$ & $79 \pm 21$ & $0.29 \pm 0.09$ \\
\hline $\begin{array}{c}\text { S- } \\
\text { BUPI }\end{array}$ & $56.0 \pm 4.0$ & $579 \pm 63$ & $105 \pm 11$ & $51 \pm 10$ & $343 \pm 39$ & $445 \pm 47$ & $104 \pm 19$ & $74 \pm 14$ & $0.25 \pm 0.13$ \\
\hline LIDO & $54.1 \pm 4.4$ & $561 \pm 103$ & $106 \pm 22$ & $58 \pm 12$ & $339 \pm 39$ & $455 \pm 27$ & $97 \pm 14$ & $73 \pm 16$ & $0.23 \pm 0.10$ \\
\hline
\end{tabular}


Table 2. Cross analysis between clusters identified by HAC, groups (BUPI, ROPI, S-BUPI, LIDO), and periods of the experiment: $\mathrm{T} 0+\mathrm{T} 1$ : baseline to $\mathrm{T} 0+90 \mathrm{sec}$. $\mathrm{T} 2+\mathrm{T} 3$ : $\mathrm{T} 0+120$ to T0+420sec. Data are exposed in percentages of total number of dots for each group of LA. Subsets are grouped according to the dendogram provided by HAC (clusters $1+2$ : severe alteration of ECG variables, clusters 3+4: intermediary alterations, clusters 5+6: moderate alterations).

\begin{tabular}{|c|c|c|c|c|}
\hline period & Local Anaesthetic & Clusters 1+2 & Clusters 3+4 & Clusters 5+6 \\
\hline \multirow{4}{*}{ T1+T2 } & ROPI & $15.2 \%$ & $1.8 \%$ & $11.6 \%$ \\
\cline { 2 - 5 } & BUPI & $8.0 \%$ & $7.0 \%$ & $17.0 \%$ \\
\cline { 2 - 5 } & S-BUPI & $6.3 \%$ & $3.6 \%$ & $18.6 \%$ \\
\cline { 2 - 5 } & LIDO & $3.6 \%$ & $0.9 \%$ & $24.1 \%$ \\
\hline \multirow{3}{*}{ T3+T4 } & ROPI & $51.8 \%$ & $8.0 \%$ & $11.6 \%$ \\
\cline { 2 - 5 } & BUPI & $50.0 \%$ & $18.0 \%$ & $0 \%$ \\
\cline { 2 - 5 } & S-BUPI & $25.0 \%$ & $41.1 \%$ & $5.4 \%$ \\
\cline { 2 - 5 } & LIDO & $13.4 \%$ & $35.7 \%$ & $22.3 \%$ \\
\hline
\end{tabular}

